\title{
Association of Milk and Meat Consumption with the Development of Breast Cancer in a Western Mexican Population
}

\author{
Hector R. Galván-Salazar ${ }^{a, b} \quad$ Alejandro Arreola-Cruz ${ }^{b}$ Daniela Madrigal-Pérez ${ }^{a, b}$ \\ Alejandro D. Soriano-Hernández ${ }^{a, b}$ Jose Guzman-Esquivel ${ }^{c}$ Daniel A. Montes-Galindo ${ }^{b}$ \\ Rodrigo A. López-Flores ${ }^{c}$ Francisco Espinoza-Gomez ${ }^{b}$ Iram P. Rodríguez-Sanchez ${ }^{d}$ \\ Oscar A. Newton-Sanchez ${ }^{b}$ Agustin Lara-Esqueda $^{b}$ Margarita L. Martinez-Fierro ${ }^{e}$ \\ Xochitl G. Briseño-Gomez ${ }^{a}$ Ivan Delgado-Enciso ${ }^{a, b}$
}

\author{
a Instituto Estatal de Cancerologia, Servicios de Salud del Estado de Colima, Mexico; \\ b School of Medicine, University of Colima, Mexico; \\ ${ }^{c}$ Hospital General de Zona N 1 del IMSS, Colima, Mexico; \\ dDepartment of Genetics, School of Medicine, Universidad Autonoma de Nuevo Leon, Mexico; \\ ${ }^{\mathrm{e}}$ Academic Unit of Human Medicine and Health Sciences, Universidad Autonoma de Zacatecas, Mexico
}

\section{Keywords}

Breast cancer · Risk factors · Tumorigenesis

\section{Summary}

Background: Breast cancer is a public health problem and it is the most common gynecologic neoplasia worldwide. The risk factors for its development are of both hereditary and environmental origin. Certain foods have been clearly associated with modifying the breast cancer risk. The aim of the present analysis was to evaluate the effects of cow's milk and meat consumption on the development of breast cancer in a population from Western Mexico (Colima). Material and Methods: We studied 97 patients presenting with a histopathologic diagnosis of breast cancer and 104 control individuals who did not present with the disease (Breast Imaging Report and Data System (BI-RADS) 1-2). $80 \%$ of the population belonged to a low socioeconomic stratum. The main clinical characteristics were analyzed along with the lifetime consumption of meat and milk. Results: High milk consumption increased the breast cancer risk by 7.2 times $(p=0.008)$ whereas the consumption of meat was not significantly associated with the disease. Conclusions: High consumption of cow's milk was a risk factor for the development of breast cancer. Further studies are needed to evaluate the effects of dietary patterns on the development of breast cancer in diverse populations with ethnic, cultural, and economic differences.

(c) 2015 S. Karger GmbH, Freiburg

\section{Introduction}

Breast cancer is the most common gynecologic neoplasia [1-3] and the second most frequent cause of death by cancer after lung cancer $[2,4,5]$. Different genetic and environmental factors influence its development [6]. Among the latter, the consumption of milk and meat has been controversially associated with breast cancer.

Meat consumption has been identified as a risk factor for the development of numerous types of cancer, associated with the frequency of consumption, the type of meat consumed [7,8], and how it is processed [6]. Compared with Mexico, countries like Argentina and Uruguay, where meat consumption is high, also have relatively high incidence rates of breast cancer [9]. Even though such facts are striking, many studies have found no association between the development of breast cancer and certain dietary patterns [8-11].

The consumption of milk and other dairy products is another environmental factor with a still controversial role in the pathogeny of breast cancer. Some studies indicate that milk consumption is associated with breast cancer development [12], relating it to the increased intake of estrogen metabolites [13]; others point out that dairy products, with the exception of milk, are a clear protective factor [14], and still others demonstrate no association with the pathology [11, 15-17].

The importance of the present study is that it produces evidence regarding the association of milk and meat consumption with the development of breast cancer in a western Mexican population.

\section{KARGER}

Fax +497614520714

\section{() 2015 S. Karger GmbH, Freiburg}

$1661-3791 / 15 / 0106-0393 \$ 39.50 / 0$
Dr. Ivan Delgado Enciso

School of Medicine at the University of Colima

and Instituto Estatal de Cancerologia, Servicios de Salud del Estado de Colima

Av. Universidad 333, Colonia Las Viboras, 28040 Colima, Mexico

ivan_delgado_enciso@ucol.mx 


\section{Methods}

In this study, 97 women presenting with breast cancer and 104 healthy women with normal mammograms (American College of Radiology (ACR) Breast Imaging Reporting and Data System (BI-RADS) 1 or 2) at the Instituto Estatal de Cancerología (IEC) in Colima were included. Once statements of informed consent were signed, medical histories for each participant were elaborated. The IEC case records of the patients forming the case group were reviewed, taking into account the tumor/node/metastasis (TNM) classification, histologic tumor type, etc.

Selection criteria for the control group individuals were: (1) that their routine mammograms were carried out at the same hospital in which the breast cancer patients were treated, (2) that they had a normal mammogram (BIRADS 1-2), (3) that they belonged to the same age group (less than a 5-year difference) as the patients of the breast cancer group (individuals were paired by age group), and (4) that they had no personal history of cancer. Additionally, all study participants were non-blood-related Mexican mestizo subjects from the State of Colima, Mexico. None of the participants considered themselves to be vegetarians.

Of the study population, $80 \%$ belonged to a low social stratum with the following characteristics: a family of 4-6 members, farmers or laborers, minimum wage income, no economic stability (a secure line of work), and a dwelling, generally rented, with 1-2 improvised bedrooms. $15 \%$ of the study population belonged to a middle social stratum, corresponding to a family with 4-6 members, laborers or employees, income above the minimum wage, homeowners with 2-3-bedroom houses. Only 5\% of the population belonged to an upper social stratum. This information was taken from socioeconomic data cards filled out by the personnel from the social work service of the hospital where the study was conducted. The present study was approved by the ethics committees of the School of Medicine of the Universidad de Colima and the IEC.

\section{Definitions}

A medical history was elaborated for each of the participants (including histopathologic and immunohistochemical reports on the tumors). Breast cancer patients were categorized into stages according to the TNM classification. The presence of metastasis was evaluated with a liver function test, chest X-ray, abdominal ultrasound scan, and bone scintigraphy. As part of the anamnesis, the frequency of milk and meat consumption was asked. $85 \mathrm{~g}$ of cooked meat and $240 \mathrm{ml}$ of milk, per ingestion, were the portions that were evaluated [18]. Certain varieties of meat that can reduce (fish and seafood) or increase (luncheon meat) the risk for certain types of cancers were not among the study aims of this analysis, and so their consumption was not taken into consideration. This aspect was made clear to the patients during the interview $[19,20]$. Consumption was understood as the habitual intake during the majority of the individual's lifetime. In the group of breast cancer patients, it was emphasized that consumption did not refer to dietary changes that were made after the cancer diagnosis. The food-frequency questionnaire uses an open-ended format, providing subjects with the option of answering in terms of frequency per day, week, or month [21]. Consumption was categorized as: high (daily or at least once a week), moderate (at least once every 15 days, low (at least once every 2 months), null (less than 5 times a year or never). The rationale for the use of the consumption frequency was based on previous reports [22]. In addition, the foodfrequency estimates were converted to times consumed per month [21]. Smoking was defined as the smoking of 100 or more cigarettes during the patient's lifetime [23]. Alcoholism was regarded as the regular consumption of 20-40 g of alcohol daily; a standard drink contains approximately 12-14 g of alcohol. Lactation was considered positive when the mother breastfed 1 or more children for 6 months. Gestation was a pregnancy of 28 weeks or more. The use of hormonal contraceptives was regarded as positive when they were used for a period equal to or above 5 years [10]

\section{Statistical Analysis}

Student's t-test was used to compare the mean values of the measurement variables (normally distributed). The qualitative data were compared through the chi-square test. The association between food consumption and the risk for
Table 1. Distribution of the main clinical characteristics of the study subjects

\begin{tabular}{lccc}
\hline Variables & $\begin{array}{l}\text { Case } \\
(\mathrm{n}=97)\end{array}$ & $\begin{array}{l}\text { Control } \\
(\mathrm{n}=104)\end{array}$ & $\mathrm{P}$ \\
\hline Smoking & $7.2 \%$ & $8.6 \%$ & 0.495 \\
Diabetes & $12.4 \%$ & $14.4 \%$ & 0.427 \\
Hypertension & $23.7 \%$ & $22.1 \%$ & 0.833 \\
BMI & $27.1 \pm 4.0$ & $27.8 \pm 4.5$ & 0.222 \\
Pregnancies, $\mathrm{n}$ & $3.4 \pm 2.8$ & $4.3 \pm 2.5$ & 0.044 \\
Pregnancies (yes/no) & $63.9 / 36.1 \%$ & $78.8 / 21.2 \%$ & 0.022 \\
Lactation (yes/no) & $55.7 / 44.3 \%$ & $72.1 / 27.9 \%$ & 0.013 \\
Hormonal contraceptive & $17.5 \%$ & $11.5 \%$ & 0.228 \\
\hline
\end{tabular}

$\mathrm{BMI}=$ Body mass index

breast cancer was estimated by odds ratios (ORs) and 95\% confidence intervals (CIs) (crosstabs procedure). They were calculated, controlling other risk factors, using the Mantel-Haenszel ( $\mathrm{MH}$ ) method for stratified analysis. The $\mathrm{MH}$ method is a technique that generates an estimate of an association between an exposure and an outcome after adjusting for confounding, or taking it into account. The method is used with a dichotomous outcome variable and a dichotomous risk factor $[24,25]$. In our study, stratification was carried out to control 2 confounding factors: gestation (yes/no) and lactation (yes/no). All statistical analyses were performed with the software SPSS version 2.0 (IBM, Armonk, NY, USA).

\section{Results}

The mean age was 50.77 (standard deviation (SD) 7.51) and 51.38 (SD 13.64) years in the controls and cases, respectively. There was no significant difference in this variable $(\mathrm{P}=0.69)$. Other characteristics of the population studied are summarized in table 1 , where it can be seen that there were significant differences only in the variables of gestation and lactation, which were lower in the case group. With respect to tumor histology in the case group, ductal cancer predominated in $87.6 \%$, followed by the lobular, papillary, and mucinous types at $6.5 \%, 3.1 \%$, and $3.1 \%$, respectively. The clinical stage of cancer was 0 in $14.4 \%$ of the cancer patients, IA in $11.3 \%$, IB in $3.1 \%$, IIA in $33.0 \%$, IIB in $25.7 \%$, IIIA in $8.2 \%$, IIIB in $4.1 \%$, and IV in $0 \%$. Overexpression of the human epidermal growth factor receptor 2 (HER2), the progesterone receptor, and the estrogen receptor was positive in $16.5 \%, 72.2 \%$, and $77.3 \%$, respectively.

As can be seen in table 2, high consumption of meat showed no significant difference when compared with null or low consumption. However, the risk for breast cancer was 7 times greater with high milk consumption, compared with null or low consumption. It should be mentioned that the gestation and lactation variables were adjusted for these analyses, thus avoiding bias from these confusion variables. In agreement with the previous result, the consumption frequency per month was, on average, 21.0 and 18.0 for milk ( $\mathrm{p}=0.02)$ and 8.7 and $9.1(\mathrm{p}=0.06)$ for meat, in cases and controls, respectively. It is important to point out that $95 \%$ of the women stated that, throughout their lives, they had drunk whole cow's milk, and 5\% had drunk low-fat cow's milk. 
Table 2. Milk and meat consumption frequencies and their associations with breast cancer

\begin{tabular}{lrrllll}
\hline $\begin{array}{l}\text { Consumption } \\
\text { frequency }\end{array}$ & $\begin{array}{l}\text { Controls, } \\
\%\end{array}$ & $\begin{array}{l}\text { Cases, } \\
\%\end{array}$ & $\begin{array}{l}\text { Crude OR } \\
(95 \% \mathrm{CI})\end{array}$ & $\mathrm{P}$ & $\begin{array}{l}\text { Adjusted OR } \\
(95 \% \mathrm{CI})\end{array}$ & $\mathrm{P}$ \\
\hline Meat & & & & & & \\
$\quad$ High & 83 & 73 & $0.67(0.26-1.71)$ & 0.27 & $0.63(0.24-1.68)$ & 0.36 \\
$\quad$ Moderate & 10 & 17 & & & & \\
$\quad$ Low & 4 & 3 & & & & \\
$\quad$ Null & 3 & 7 & & & & \\
Milk & & & & & & \\
$\quad$ High & 83 & 93 & $5.58(1.5-19.8)$ & 0.003 & & \\
$\quad$ Moderate & 2 & 4 & & & & \\
$\quad$ Low & 12 & 1 & & & & \\
$\quad$ Null & 3 & 2 & & & & \\
\hline
\end{tabular}

${ }^{*}$ Adjusting the gestation (yes/no) and lactation (yes/no) variables by the MH method; OR: high vs. null + low consumption.

\section{Discussion}

High consumption of cow's milk was found to be a factor increasing the risk for presenting with breast cancer in the population studied. These results concur with those reported by Hjartåker et al. [11] and Farlow [26] who postulated that milk consumption is a risk factor for breast cancer. In spite of that, there are also reports in which no such association was indicated. Zhang and Kesteloot [16] analyzed the general milk consumption and the incidence of this neoplasia in different countries and reported that milk consumption did not substantially change the risk for breast cancer. This last result does not concur with that of our study, which could be due to the large methodological differences between the 2 analyses. It has been suggested that high milk consumption results in the ingestion of cow estrogen metabolites as well as a high caloric intake, both of which are risk factors for developing breast cancer. It should be noted that, in contrast, dairy products have been clearly described as protective factors [14]. Nevertheless, this aspect was not determined in the present study.

On the other hand, it has previously been suggested that meat can also be a risk factor for developing breast cancer, but the results were inconclusive $[7,8]$ as well as controversial, given that there are also studies stating that non-vegetarian eating habits (consumption of animal products) per se does not elevate the breast cancer risk and that traditional manufacturing and cooking methods can have a more relevant influence than the type of food [27]. The methodological designs of the reports on this subject vary greatly, with a large number of variables involved, making it difficult to arrive at a widely acceptable conclusion [28]. We did not observe an association between red meat consumption and breast cancer in our study. On the contrary, meat consumption was lower in the patients with breast cancer. It is worth noting that $80 \%$ of the population studied had a low economic level, with limited access to expensive food such as meat. This particularity could be the reason why the consumption of meat at least once a week (high consumption) in this population had the tendency to be a protective factor. Future studies with a larger sample number are needed in order to determine the effect of meat consumption in non-vegetarian populations in which a significant percentage of subjects do not frequently consume meat for socioeconomic reasons.

An important aspect of the present study was the confirmation of the protective role of gestation and lactation in the development of breast cancer. Just as in a large number of epidemiologic studies, it was found that patients with this cancer had a lower number of pregnancies and breastfed less, when compared with healthy women [29]. At the commencement of pregnancy, the breast undergoes a cyclical transformation during which it matures from a resting, nonfunctional gland to a milk-producing organ, which then gradually reverts back to quiescence after cessation of lactation. Data suggest that the pregnancy-lactation cycle permanently alters the molecular histology of the breast and influences the breast cancer risk [30].

In conclusion, high milk consumption was a risk factor for developing breast cancer in this study population. Meat consumption was not significantly associated with the development of this neoplasia. Further studies are needed to evaluate the effects of the dietary pattern on breast cancer development in populations with ethnic, cultural, and economic differences.

\section{Disclosure Statement}

The authors have no direct or indirect commercial financial incentive associated with publishing the manuscript. This research was not funded by commercial companies or other extra-institutional funds. The authors declare no conflict of interest. 


\section{References}

1 Arce C et al.: Cáncer de mama. Cancerología 2011;6: 77-86.

2 Cárdenas-Sánchez J, Erazo-Valle A, Maafs-Molina E: Consenso Nacional sobre diagnóstico y tratamiento del cáncer mamario, ed 4. Rio de Janeiro, Elsevier, 2011, pp 6-8.

3 Guliano A, Hurvitz S: Trastornos de las mamas; Papadakis M, McPhee SJ, eds : Diagnóstico Clínico y Tratamiento, ed 50. New York, McGraw-Hill 2012, pp $697-$ 698.

4 Macon MB, Fenton SE: Endocrine disruptors and the breast: early life effects and later life disease. J Mammary Gland Biol Neoplasia 2013;18:43-61.

5 De Stefani E, Boffetta P, Ronco AL, Deneo-Pellegrini $\mathrm{H}$, Correa P, Acosta G, Mendilaharsu M, Luaces ME, Silva C: Processed meat consumption and risk of cancer: a multisite case-control study in Uruguay. $\mathrm{Br} \mathrm{J}$ Cancer 2012;107:1584-1588.

- 6 Karimi Z, Jessri M, Houshiar-Rad A, Mirzaei HR, Rashidkhani B: Dietary patterns and breast cancer risk among women. Public Health Nutr 2014;17:1098-1106.

7 Fung TT, Hu FB, Holmes MD, Rosner BA, Hunter DJ, Colditz GA, Willett WC: Dietary patterns and the risk of postmenopausal breast cancer. Int J Cancer 2005; 116:116-121.

8 Torres-Sánchez L, Galván-Portillo M, Lewis S, Gómez Dantés H, López-Carrillo L: Diet and breast cancer in Latin-America. Salud Publica Mex 2009;51(suppl 2):S181-S190.

9 Voguel V: Epidemiologia del cáncer de mama; in Bland KI, Copeland EM, eds: La Mama, Manejo Multidisciplinario de las Enfermedades Benignas y Malignas, ed 3. Buenos Aires, Médica Panamericana, 2007 pp 355-366.

10 Missmer SA, Smith-Warner SA, Spiegelman D, Yaun SS, Adami HO, Beeson WL, van den Brandt PA, Fraser GE, Freudenheim JL, Goldbohm RA, Graham S, Kushi LH, Miller AB, Potter JD, Rohan TE, Speizer FE, Toniolo P, Willett WC, Wolk A, Zeleniuch-Jacquotte A Hunter DJ: Meat and dairy food consumption and breast cancer: a pooled analysis of cohort studies. Int J Epidemiol 2002;31:78-85.
Hjartåker A, Laake P, Lund E: Childhood and adult milk consumption and risk of premenopausal breast cancer in a cohort of 48,844 women - the Norwegian women and cancer study. Int J Cancer 2001;93:888-893.

12 Hanf V, Körner W: Consumption of cow's milk and possible risk of breast cancer. Breast Care 2010;5:44-45.

13 Dong JY, Zhang L, He K, Qin LQ: Dairy consumption and risk of breast cancer: a meta-analysis of prospective cohort studies. Breast Cancer Res Treat 2011;127: 23-31.

14 Moorman PG, Terry PD: Consumption of dairy products and the risk of breast cancer: a review of the literature. Am J Clin Nutr 2004;80:5-14.

5 Parodi PW: Dairy product consumption and the risk of breast cancer. J Am Coll Nutr 2005;24(6 suppl): 556S-568S.

16 Zhang J, Kesteloot H: Milk consumption in relation to incidence of prostate, breast, colon, and rectal cancers: is there an independent effect? Nutr Cancer 2005;53: $65-72$

17 Institute of Grocery Distribution: Portion Size: A Review of Existing Approaches. Watford, Institute of Grocery Distribution, 2008.

18 Medina-Mora MA, Peña-Corona MP, Cravioto P, Villatoro J, Kuri P: Del tabaco al uso de otras drogas: el uso temprano de tabaco aumenta la probabilidad de usar otras drogas. Salud Publica Mex 2002;44:S109S115.

19 Domingo JL: Nutrients and chemical pollutants in fish and shellfish. Balancing health benefits and risks of regular fish consumption. Crit Rev Food Sci Nutr 2014, in press. DOI: 10.1080/10408398.2012.742985

20 Zhu H, Yang X, Zhang C, Zhu C, Tao G, Zhao L, Tang S, Shu Z, Cai J, Dai S, Qin Q, Xu L, Cheng H, Sun X: Red and processed meat intake is associated with higher gastric cancer risk: a meta-analysis of epidemiological observational studies. PLoS One 2013;8:e70955.
1 Drewnowski A, Hann C: Food preferences and reported frequencies of food consumption as predictors of current diet in young women. Am J Clin Nutr 1999; 70:28-36.

22 Steyn NP, Labadarios D, Nel JH: Factors which influence the consumption of street foods and fast foods in South Africa - a national survey. Nutr J 2011;10:104.

23 World Health Organization: Cancer de mama: prevención y control. www.who.int/topics/cancer/breastcancer/ es/index1.html.

24 dos Santos Silva I: Cancer Epidemiology: Principles and Methods. Lyon, IARC Press, 1999.

25 LaMorte WW, Sullivan L: Confounding and effect measure modification. Boston University School of Public Health, http://sphweb.bumc.bu.edu/otlt/MPH Modules/BS/BS704-EP713_Confounding-EM/BS704EP713_Confounding-EM7.html, 2014

26 Farlow DW, Xu X, Veenstra TD: Quantitative measurement of endogenous estrogen metabolites, risk factors for development of breast cancer, in commercial milk products by LCMS/MS. J Chromatogr B Analyt Technol Biomed Life Sci 2009;877:1327-1334.

27 Rossi RE, PericleousM, Mandair D, Whyand T, Caplin ME: The role of dietary factors in prevention and progression of breast cancer. Anticancer Res 2014;34: 6861-6875.

28 Hanf V, Gonder U: Nutrition and primary prevention of breast cancer: foods, nutrients and breast cancer risk. Eur J Obstet Gynecol Reprod Biol 2005;123:139-149.

29 Bernier MO, Plu-Bureau G, Bossard N, et al.: Breastfeeding and risk of breast cancer: a metaanalysis of published studies. Hum Reprod Update 2000;6:374-386.

30 Faupel-Badger JM, Arcaro KF, Balkam JJ, et al.: Postpartum remodeling, lactation, and breast cancer risk: summary of a National Cancer Institute-sponsored workshop. J Natl Cancer Inst 2013;105:166-174. 